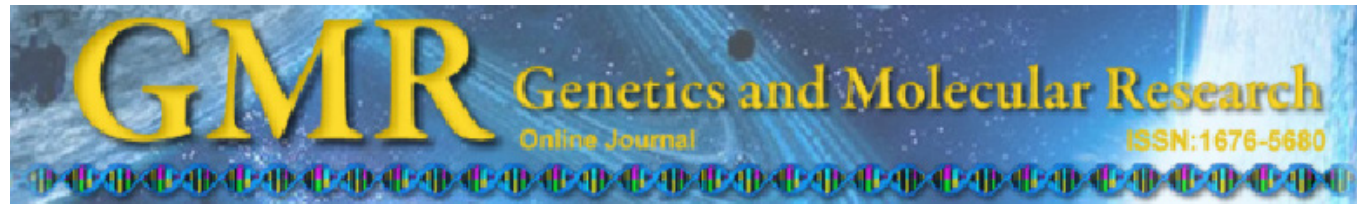

Short Communication

\title{
Mutations in NPHS2 (podocin) in Mexican children with nephrotic syndrome who respond to standard steroid treatment
}

\author{
J.S. Carrasco-Miranda ${ }^{1}$, R. Garcia-Alvarez ${ }^{2}$, R.R. Sotelo-Mundo ${ }^{1}$, \\ O. Valenzuela ${ }^{3}$, M.A. Islas-Osuna ${ }^{1}$ and N. Sotelo-Cruz ${ }^{4}$ \\ ${ }^{1}$ Centro de Investigación en Alimentación y Desarrollo, Hermosillo, \\ Sonora, México \\ ${ }^{2}$ Hospital Infantil del Estado de Sonora, Hermosillo, Sonora, México \\ ${ }^{3}$ Departamento de Ciencias Químico-Biológicas, Universidad de Sonora, \\ Hermosillo, Sonora, México \\ ${ }^{4}$ Departamento de Medicina y Ciencias de la Salud, Universidad de Sonora, \\ Hermosillo, Sonora, México
}

Corresponding authors: N. Sotelo-Cruz / M.A. Islas-Osuna

E-mail: nsotelo@guaymas.uson.mx / islasosu@ciad.mx

Genet. Mol. Res. 12 (2): 2102-2107 (2013)

Received August 8, 2012

Accepted January 27, 2013

Published June 24, 2013

DOI http://dx.doi.org/10.4238/2013.June.24.1

\begin{abstract}
Human nephrotic syndrome has been related to mutations in glomerular proteins. Mutations in the NPHS2 gene that encodes podocin have been described as responsible for steroidresistant nephrotic syndrome. It has been advised to test for NPHS2 mutations in parallel or before giving steroid treatment in nephrotic syndrome patients in order to avoid unnecessary therapy. We identified NPHS2 mutations in Mexican children with nephrotic syndrome. The study included 13 children with nephrotic syndrome and 2 healthy control individuals; 8 patients were steroid-resistant and 5 were steroidsensitive. We analyzed the 3rd exon of NPHS2 by DNA sequencing. Podocin heterozygous missense mutations L139R and L142P were found; the former was found in both steroid-sensitive and steroid-
\end{abstract}


resistant children, while the latter was found in a steroid-resistant child. We conclude that NPHS2 mutations should be investigated to help decide the course of treatment in nephrotic syndrome patients.

Key words: Podocin; Nephrotic syndrome; Mexican children; Mutation

\section{INTRODUCTION}

Nephrotic syndrome (NS) is defined as a combination of proteinuria, hypoalbuminemia, edema, and hyperlipidemia. Approximately $80 \%$ of all children with sporadic NS respond to steroid treatment. For decades, NS has been separated into 2 broad categories on the basis of the patient's response to standard steroid therapy, i.e., steroid-sensitive NS (SSNS) and steroid-resistant NS (SRNS) (Ruf et al., 2004). This syndrome is related to the NPHS2 gene, which codes for an exclusive glomerular protein (podocin) that participates in blood filtration and cell signaling (Somlo and Mundel, 2000; Huber and Benzing, 2005). Podocin mutations are apparently restricted to SRNS (Niaudet, 2004a; Otukesh et al., 2009; Maddalena et al., 2011); they represent approximately $40 \%$ of familial SRNS patients and have also been found in $10-30 \%$ of sporadic SRNS cases in groups from European and Middle Eastern countries (Caridi et al., 2001; Karle et al., 2002; Ruf et al., 2004) and 20\% of NS in the Japanese population (Maruyama et al., 2003). The identification of NPHS2 mutations in NS patients is important for therapeutic decisions and genetic counseling, and according to several authors, patients should be tested for mutations in this gene before receiving immunosuppressive therapy (Karle et al., 2002; Niaudet, 2004a; Ruf et al., 2004; Caridi et al., 2005).

Inter-ethnic differences have also been suggested to play a role in the incidence of NPHS2 mutations (Andreoli, 2004; Özçakar et al., 2006). Mutations in this gene in Mexican patients with NS remain largely unknown, since databases lack this information to date. Thus, we determined the presence of mutations in the most commonly tested exon of the NPHS2 gene, which is involved in SRNS.

\section{MATERIAL AND METHODS}

\section{Patients and controls}

We examined 15 Mexican children, including 8 diagnosed with SRNS and 5 with SSNS and 2 healthy children. All patients presented normal renal function (data not shown). These cases were seen at State Children's Hospital in Hermosillo, Sonora, Mexico, under parents' consent and approved protocols of the Hospital Bioethics committee. NS patients were admitted to the hospital from May to September 2010. Parental consanguinity was not reported. Nephrotic syndrome was defined as proteinuria $\left(>40 \mathrm{mg} \cdot \mathrm{m}^{-2} \cdot \mathrm{h}^{-1}\right)$, hypoalbuminemia $(<2.5 \mathrm{~g} / \mathrm{dL}$ ), hyperlipidemia (serum total cholesterol $>200 \mathrm{mg} / \mathrm{dL}$ ), and edema. Familial and sporadic NS types were also determined by familial history. SRNS was defined as the failure to respond to 6- to 8-week daily administration of $2 \mathrm{mg} / \mathrm{kg}$ prednisone from the onset of the disease. 


\section{DNA extraction and detection of NPHS2 gene mutations}

Genomic DNA was extracted and purified from peripheral whole blood samples using a QIAmp kit (Qiagen, Valencia, CA, USA). The primers used were designed based on GenBank NG_007535.1. DNA (100 ng) was amplified using 1 U Platinum Taq DNA polymerase (Invitrogen, Life Technologies, Mexico) in a $25-\mu \mathrm{L}$ reaction mixture, which consisted of $2.5 \mu \mathrm{L} 10 \mathrm{X}$ PCR buffer, $2.0 \mu \mathrm{L} 10 \mathrm{mM}$ dNTPs, $10 \mu \mathrm{M}$ primers, and $1.5 \mu \mathrm{L} 25 \mathrm{mM} \mathrm{MgCl}$. The PCR conditions were as follows: 1 cycle at $95^{\circ} \mathrm{C}$ for $10 \mathrm{~min}$, a second stage consisting of 29 cycles at $95^{\circ}(1 \mathrm{~min})$, $55^{\circ}(1 \mathrm{~min})$, and $72^{\circ} \mathrm{C}(1 \mathrm{~min})$, and a third consisting of 1 cycle at $72^{\circ} \mathrm{C}$ for $7 \mathrm{~min}$. Aliquots $(7 \mu \mathrm{L})$ of the PCR product were electrophoresed on $2 \%$ agarose gels and visualized under UV illumination after staining with Sybr Safe (Invitrogen). The primers utilized for amplification and sequencing of the 3rd exon of the NPHS2 gene were as follow: forward: 5'-GGGAAAGTTGGCCATG-3' and reverse: 5'-GGCTCTCTGTACCAATTCTCTC-3'. The PCR products were purified using a QIAquick PCR Purification kit (Qiagen). Sequencing of both strands of the 3rd exon of the NPHS2 gene was performed at the University of Arizona Genetics Core sequencing laboratory (Tucson, AZ, USA). Sequences obtained were analyzed using the Blast algorithm from NCBI and compared against the amino acid sequence of NPHS2 (GenBank NP_055440).

\section{RESULTS}

The 13 patients with confirmed NS had normal renal function, and the median age of onset was 3.5 years. Eight patients showed primary steroid-resistance and 5 patients were initially steroid-sensitive. Since none of the patients had a family history of NS, we identified these cases as sporadic NS. Patients had cholesterol levels above $200 \mathrm{mg} / \mathrm{dL}$, ranging from 218 to $1060 \mathrm{mg} /$ dL. Three of the 13 NS patients (23\%) showed normal triglycerides levels under $200 \mathrm{mg} / \mathrm{dL}$ with no distinctions between steroid-resistant and steroid-sensitive patients (Table 1).

Table 1. Clinical data and podocin mutations in 13 children with nephrotic syndrome and 2 healthy controls.

\begin{tabular}{lclcr}
\hline Individuals & Drug response & Mutation & Cholesterol (mg/dL) & Triglycerides (mg/dL) \\
\hline 1 & S & L139R & 349 & 288 \\
2 & S & No & 533 & 157 \\
3 & S & No & 350 & 261 \\
4 & S & L139R & 245 & 117 \\
$5^{\mathrm{HD}}$ & $\mathrm{R}$ & L139R & 575 & 463 \\
6 & $\mathrm{R}$ & No & 438 & 752 \\
7 & $\mathrm{R}$ & No & 265 & 411 \\
8 & $\mathrm{R}$ & No & 218 & 91 \\
9 & $\mathrm{R}$ & No & 382 & 311 \\
10 & $\mathrm{R}$ & No & 1060 & 796 \\
11 & $\mathrm{R}$ & L142P & 358 & 1993 \\
12 & $\mathrm{R}$ & No & 401 & 611 \\
13 & $\mathrm{~S}$ & No & 154 & 517 \\
$14^{*}$ & NT & No & 130 & 154 \\
$15^{*}$ & NT & No & 123 \\
\hline
\end{tabular}

*Healthy controls; $\mathrm{S}$ = steroid-sensitive; $\mathrm{R}=$ steroid-resistant; $\mathrm{NT}=$ no treatment; ${ }^{\mathrm{HD}}$ hepatic damage.

Mutational analysis was carried out in 15 children, where 2 of them were healthy. We analyzed the sequence of the NPHS2 gene exon 3, and 2 novel missense mutations were found in 4 of the patients $(26.6 \%)$ (Table 1$)$. 
In steroid-resistant patients, we observed 6 of 8 individuals with no mutations in NPHS2 gene exon 3, with cholesterol levels ranging from 218 to $682 \mathrm{mg} / \mathrm{dL}$ and triglycerides from 91 to $796 \mathrm{mg} / \mathrm{dL}$. However, 1 individual with a heterozygous missense mutation L142P had a cholesterol level of $1060 \mathrm{mg} / \mathrm{dL}$ and triglycerides of $1993 \mathrm{mg} / \mathrm{dL}$.

Three patients showed the heterozygous missense mutation L139R, where 2 of them were identified as steroid-sensitive patients. The corticoid-resistant patient with this missense mutation displayed hepatic damage and higher serum lipid levels compared to the 2 others. Cholesterol ranged from 245 to $575 \mathrm{mg} / \mathrm{dL}$ and triglycerides ranged from 117 to $463 \mathrm{mg} / \mathrm{dL}$ in patients with mutation L139R. The rest of the patients and controls had no mutation in the NPHS2 gene exon 3.

\section{DISCUSSION}

Previous studies on the frequency of NPHS2 mutations in different populations showed that ethnicity plays an important role; however, there is no consensus on which exon is more critical for predicting NS and which mutations are most deleterious for the patient (Otukesh et al., 2009). However, exon 3 is the most recurrent source of mutations in the NPHS2 gene. Ruf et al. (2004) found that almost 50\% of the missense mutations reported are concentrated in this region. One of the most common mutations, R138Q, is localized in exon 3 and it is mainly reported in the European population, including countries such as Italy, France, and Germany (Niaudet, 2004b; Löwik et al., 2009). However, it has also been found in the Greek population (Megremis et al., 2008), and we suggest that it would be worthwhile searching for this mutation or any variation through this exon in the Mexican population.

We found 2 novel missense mutations in the NPHS2 gene exon 3 and no incidence of R138Q in Mexican pediatric NS patients. One of them appeared in a corticoid-resistant NS patient with exacerbated serum lipid levels (L142P). Another mutation (L139R) appeared in 2 of 5 corticoid-sensitive and 1 of 8 corticoid-resistant patients, where this last one developed hepatic damage and markedly higher lipid levels than corticoid-sensitive patients with the same mutation. The hepatic damage and altered lipid levels could be factors that contribute to resistance to corticoid treatment in the patient according to Ueda et al. (2011). Both missense mutations affect amino acids that are highly conserved across many species (Figure 1), which denotes their importance in the protein's function and its possible role in the cause of NS.

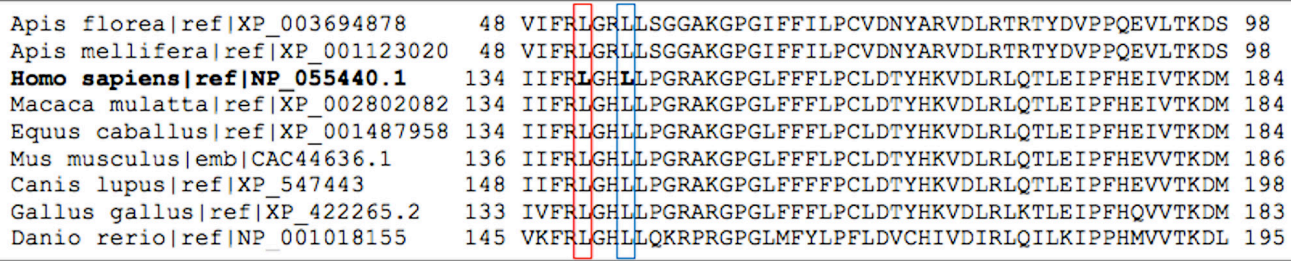

Figure 1. Alignment of podocin amino acids of different species. Red box corresponds to invariant leucine residue (human L139) and blue box corresponds to invariant human L142. GenBank accession numbers are included after the scientific name of the organism.

Due to the position and change in the polarity of the amino acid in the mutation L139R, we suggest that this mutant podocin is not able to associate with lipid rafts in the plasma membrane and may not be able to recruit nephrin to the lipid rafts, losing its ability to 
enhance nephrin signaling, as in a patient carrying the R138Q mutation (Huber et al., 2003), resulting in NS. However, according to observed in silico secondary structure prediction (Garnier et al., 1996) (Table 2), we believe that in the mutation L139R the conformational change in the protein may not be drastic enough to impair the molecular mechanism of action of corticoids, and that the patients can respond to treatment. Steroid resistance in the patient with the same mutation could be due to various factors that can affect response to treatment such as changes in corticoid receptors, low levels of corticoid transporter proteins due to hepatic damage, or the high persistent hyperlipidemia (Ueda et al., 2011). Therefore, it is suggested that the mutation L139R is not related to treatment resistance because it is present in corticoidsensitive patients as well as in a corticoid-resistant patient (Table 1).

Table 2. Prediction of secondary structure composition of human podocin.

\begin{tabular}{lccc}
\hline Structure & Normal podocin & Mutant L139R & Mutant L142P \\
\hline Alpha helix & $39.43 \%$ & $39.43 \%$ & $37.60 \%$ \\
Extended strand & $12.27 \%$ & $12.27 \%$ & $13.84 \%$ \\
Random coil & $48.30 \%$ & $48.30 \%$ & $48.56 \%$ \\
\hline
\end{tabular}

These results can be supported by sporadic cases where the heterozygous missense mutations such as R138Q (Ruf et al., 2004), which has been proven to cause SN (Huber et al., 2003), homozygous L169P (Caridi et al., 2001), or S211T (Caridi et al., 2005), all excluded as polymorphism, are present in SSNS patients. The specific molecular mechanism of action for immunosuppressive therapy in SN patients has not been well elucidated.

Some authors argue that mutations in podocin are an important cause of SRNS. Ruf et al. (2004) argue that homozygous or compound heterozygous are directly related to steroidresistant patients. Karle et al. (2002) found 4 German families with SRNS and heterozygous mutations. Yu et al. (2005) reported on 1 of 23 SRNS patients, who showed a single heterozygous missense mutation L361P in podocin and no mutation in control individuals. In this study, we found a heterozygous leucine-to-proline change (L142P) that could be related to resistance to steroid treatment. It is well known that proline residues disrupt secondary structure, especially alpha helices; in this case, the mutation L142P could drastically disrupt secondary structure conformation and possibly affect the function of the protein (Table 2). Furthermore, a significant change in the conformation of the protein can affect the mechanism of action of corticoids in treatment, leading to a resistance condition. However, further studies are required to elucidate the specific mechanism. This heterozygous mutation was present in 1 SRNS patient in this study.

The mutations reported here were searched as single nucleotide polymorphisms in NPHS2 for the Mexican population and none was found in available databases (Silva-Zolezzi et al., 2009).

On the basis of our results, we support a model where ethnicity plays an important role in specific NPHS2 mutations, since 2 novel mutations were found in this study. However, a larger study is needed. The relationship between NPHS2 mutations and resistance to steroid treatment in NS patients is controversial, because steroid treatment is recommended only in patients who have a non-mutant NPHS2 genotype (Karle et al., 2002; Niaudet, 2004a; Ruf et al., 2004; Caridi et al., 2005). Further study is recommended and it is underway to generate a predictive model to understand in a more thorough way the molecular etiology of NS. 


\section{ACKNOWLEDGMENTS}

We thank M. Resendiz-Sandoval for technical assistance, and we are grateful for the Molecular Biology infrastructure of CIAD as well as the clinical facilities of HIES. J.S. Carrasco-Miranda thanks CONACYT for a doctoral scholarship.

\section{REFERENCES}

Andreoli SP (2004). Racial and ethnic differences in the incidence and progression of focal segmental glomerulosclerosis in children. Adv. Ren. Replace. Ther. 11: 105-109.

Caridi G, Bertelli R, Carrea A, Di Duca M, et al. (2001). Prevalence, genetics, and clinical features of patients carrying podocin mutations in steroid-resistant nonfamilial focal segmental glomerulosclerosis. J. Am. Soc. Nephrol. 12: $2742-2746$.

Caridi G, Perfumo F and Ghiggeri GM (2005). NPHS2 (Podocin) mutations in nephrotic syndrome. Clinical spectrum and fine mechanisms. Pediatr. Res. 57: 54R-61R.

Garnier J, Gibrat JF and Robson B (1996). GOR method for predicting protein secondary structure from amino acid sequence. Methods Enzymol. 266: 540-553.

Huber TB and Benzing T (2005). The slit diaphragm: a signaling platform to regulate podocyte function. Curr. Opin. Nephrol. Hypertens. 14: 211-216.

Huber TB, Simons M, Hartleben B, Sernetz L, et al. (2003). Molecular basis of the functional podocin-nephrin complex: mutations in the NPHS2 gene disrupt nephrin targeting to lipid raft microdomains. Hum. Mol. Genet. 12: 3397-3405.

Karle SM, Uetz B, Ronner V, Glaeser L, et al. (2002). Novel mutations in NPHS2 detected in both familial and sporadic steroid-resistant nephrotic syndrome. J. Am. Soc. Nephrol. 13: 388-393.

Löwik MM, Groenen PJ, Levtchenko EN, Monnens LA, et al. (2009). Molecular genetic analysis of podocyte genes in focal segmental glomerulosclerosis - a review. Eur. J. Pediatr. 168: 1291-1304.

Maddalena G, Matteo P, Loreto G, Achille I, et al. (2011). Molecular and genetic basis of inherited nephrotic syndrome. Int. J. Nephrol. 2011: 1-15.

Maruyama K, Iijima K, Ikeda M, Kitamura A, et al. (2003). NPHS2 mutations in sporadic steroid-resistant nephrotic syndrome in Japanese children. Pediatr. Nephrol. 18: 412-416.

Megremis S, Mitsioni A, Mitsioni A, Stefanidis C, et al. (2008). Screening of mutations in the NPHS2 gene in Greek patients with autosomal-recessive steroid-resistant nephrotic syndrome. Pediatrics 121: S117.

Niaudet P (2004a). Genetic forms of nephrotic syndrome. Pediatr. Nephrol. 19: 1313-1318.

Niaudet P (2004b). Podocin and nephrotic syndrome: implications for the clinician. J. Am. Soc. Nephrol. 15: 832-834.

Otukesh H, Ghazanfari B, Fereshtehnejad SM, Bakhshayesh M, et al. (2009). NPHS2 mutations in children with steroidresistant nephrotic syndrome. Iran J. Kidney Dis. 3: 99-102.

Özçakar ZB, Cengiz FB, Cakar N, Uncu N, et al. (2006). Analysis of NPHS2 mutations in Turkish steroid-resistant nephrotic syndrome patients. Pediatr. Nephrol. 21: 1093-1096.

Ruf RG, Lichtenberger A, Karle SM, Haas JP, et al. (2004). Patients with mutations in NPHS2 (podocin) do not respond to standard steroid treatment of nephrotic syndrome. J. Am. Soc. Nephrol. 15: 722-732.

Silva-Zolezzi I, Hidalgo-Miranda A, Estrada-Gil J, Fernandez-Lopez JC, et al. (2009). Analysis of genomic diversity in Mexican Mestizo populations to develop genomic medicine in Mexico. Proc. Natl. Acad. Sci. U. S. A. 106: 86118616.

Somlo S and Mundel P (2000). Getting a foothold in nephrotic syndrome. Nat. Genet. 24: 333-335.

Ueda S, Sugimoto K, Yanagida H, Fujita S, et al. (2011). Low-density lipoprotein adsorption therapy can restore drug sensitivity for immunosuppressants via inhibitory effects upon MDR-1 gene expression. Ther. Apher. Dial. 15: 499503.

Yu Z, Ding J, Huang J, Yao Y, et al. (2005). Mutations in NPHS2 in sporadic steroid-resistant nephrotic syndrome in Chinese children. Nephrol. Dial. Transplant 20: 902-908. 